\title{
Dislocation interactions in near-alpha Titanium alloy Ti6242Si under LCF
}

\author{
Sudha Joseph*, Trevor C. Lindley, David Dye \\ Department of Materials, Royal School of Mines, Imperial College, Prince Consort Road, \\ London SW7 2BP, UK. \\ sudha.joseph@imperial.ac.uk
}

Dislocation interactions were investigated in near-alpha titanium alloy Ti6242Si after low cycle fatigue. Samples from the gauge section and the crack initiation site on the fracture surface were studied. Grain pairs with different crystallographic orientations were analysed from the gauge section to understand the dislocation interactions near the boundary. Deformation was primarily caused by planar slip, localized into slip bands in primary alpha $\left(\alpha_{\mathrm{p}}\right)$ grains. Direct slip transfer was observed within grains having similar orientations. In contrast, slip transfer resulted in a different kind of dislocation nucleation in the neighboring hard grain where there was misorientation between the grains, with the observation of cross-slip. Strain transfer was observed between highly misoriented grain pairs. Crack nucleation occurred on an $\alpha_{\mathrm{p}}$ grain by basal plane splitting, due to the large tensile stress developed by a double ended pile-up. This kind of pile-up is suggested to result from the incomplete reversibility of dislocation motion during load reversals. The observation of superjogs on the basal dislocations in the crack nucleated $\alpha_{\mathrm{p}}$ grain provides a rationale for why cracks nucleate near, rather than on, the basal plane.

\section{Introduction}

Near- $\alpha$ titanium alloys such as Ti6242Si are employed in high temperature aero-engine compressors due to their combination of specific toughness, creep resistance and 
microstructural stability at temperatures around $400-600^{\circ} \mathrm{C}[1-4]$. The component is exposed to a variety of loading regimes during service, for e.g., high stresses in the low cycle fatigue regime may be experienced at the thrust peak associated with take-off. This continues to compromise design $[5,6]$ and hence is very important to understand. Further, the Ti alloys are generally notch sensitive and so crack initiation from the microstructure is often of greater concern than in other alloy systems where lifing can mostly be considered in terms of crack growth.

Microstructural variables such as the volume fraction of primary alpha [7], its morphology [8, 9] whether the variant state is colony or basketweave [10-13] and micro- and macro-texture [1418] affect the fatigue behavior of this alloy. The macrozones may act as large structural units that deform simultaneously [14-16], with fatigue crack initiation occurring at the interface between hard-oriented and soft oriented macrozones [19].

Furthermore, it is believed that hard/soft grain pairs act as fatigue initiation sites [12, 13] and this occurs by the formation of near basal facets in the hard grains, due to load shedding by adjacent soft grains [16], [20-23]. The lack of slip transfer from the soft to hard grain will produce a sufficient stress concentration to result in the initiation of a fatigue crack in the hard grain; conversely, easy slip transfer in the microtextured regions [24] will result in homogenous plastic deformation.

In lamellar microstructures fatigue cracks initiate either within slip bands in $\alpha$ lamellae or along prior beta grain boundaries [25, 26]. In bimodal microstructures, cracking can initiate either on the interface between the lamellar microstructure and the $\alpha_{p}$ or within the $\alpha_{p}$ itself [27]; initiation also depends on the fraction and size of the $\alpha_{\mathrm{p}}$. In near- $\alpha$ alloys, such as Ti6242, with more than $50 \% \alpha_{p}$, crack nucleation is expected to occur in the $\alpha_{p}$ due to extensive grain boundary dislocation pile-up [27, 28].

In the present work, the dislocation structures produced during low cycle fatigue in Ti6246Si are investigated in detail, both in the gauge section and the fracture surface of the sample, with the 
aim of elucidating how slip transfer and grain boundary interactions more generally may contribute to fatigue crack initiation and propagation.

\section{Material and experiments}

The near alpha titanium alloy Ti-6Al-2Sn-4Zr-2Mo-0.1Si was studied in this work. Mechanical tests were conducted using Mayes servohydraulic machines with Instron 8800 controllers. Static tensile tests were carried out on dog bone shaped samples at a strain rate of $10^{-3} \mathrm{~s}^{-1}$. Low cycle fatigue (LCF) tests were carried out on cylindrical samples with a $2.9 \mathrm{~mm}$ diameter and a $15 \mathrm{~mm}$ long gauge length. The tests were performed using a trapezoidal waveform with a ramp up/down time of $1 \mathrm{~s}$, a $1 \mathrm{~s}$ hold at maximum stress of $95 \%$ of yield stress and an R ratio of 0.05 .

Dislocation analysis on LCF samples was conducted using a JEOL JEM-2100F TEM/STEM with an accelerating voltage of $200 \mathrm{kV}$. $0.5 \mathrm{~mm}$ thick discs were cut from the gauge of the failed samples normal to the loading direction, ground to 100 to $150 \mathrm{~mm}$ using $\mathrm{SiC}$ paper and electropolished using $3 \%$ perchloric acid, $57 \%$ methanol and $40 \%$ butan $1-\mathrm{ol}$ in a Tenupol at $-40^{\circ} \mathrm{C}$ and $24 \mathrm{~V}$. TEM samples from the crack initiation site were prepared using the focused ion beam (FIB) lift-out technique in a dual beam FEI Helios NanoLab 600 using a $30 \mathrm{kV}$ Ga ion beam. To protect the area of interest, a gas injection system was used to deposit a Pt-containing protective layer. Samples were made electron transparent by thinning to $150 \mathrm{~nm}$ thickness. To obtain the $\alpha_{\mathrm{p}}$ grain orientations, Transmission Kikuchi Diffraction (TKD) was carried out at an accelerating voltage of $30 \mathrm{kV}$ and working distance of $2 \mathrm{~mm}$.

\section{Results \& Discussion}

\subsection{Initial microstructure:}


The alloy had a typical bimodal microstructure with $\alpha_{\mathrm{p}}$ in the transformed $\beta$, Fig. 1 . Secondary alpha $\left(\alpha_{s}\right)$ platelets can be observed in the retained $\beta$. The volume fraction of $\alpha_{p}$ was found to be $\approx 50 \%$.

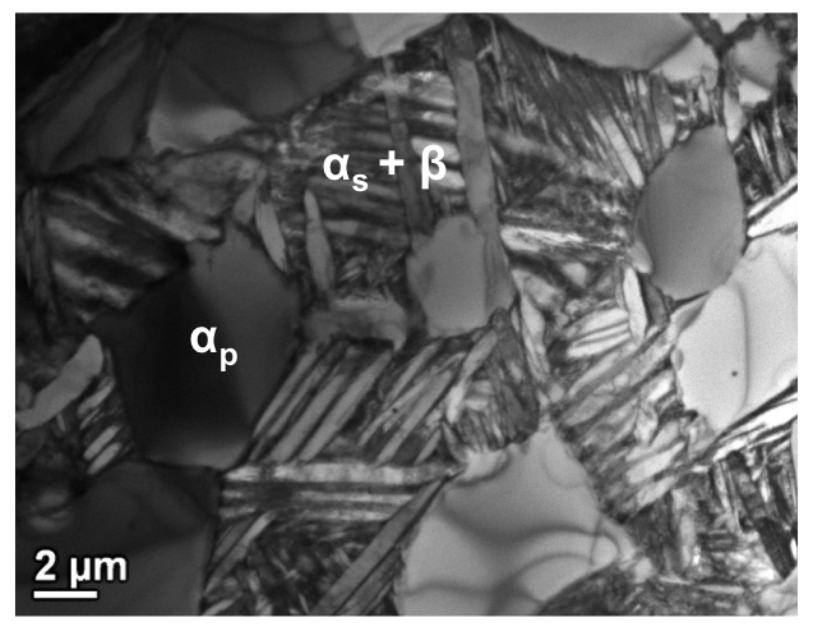

Fig. 1 Bright field TEM image showing the typical microstructure of Ti6242 alloy

\subsection{Dislocation interactions in the gauge section:}

TEM analysis was carried out in the two-beam condition under different beam directions. The dislocation Burgers vectors were identified using the invisibility criterion, along with a trace analysis to identify the slip planes. The alloy was generally found to mainly deform by planar slip in $\alpha_{\mathrm{p}}$ grains; a typical pile-up observed in an $\alpha_{\mathrm{p}}$ grain is shown in Fig. 2, which is a BF-STEM micrograph of a sample taken from the gauge section when the beam direction is $\mathrm{B}=[10 \mathrm{ll} 0]$. This a soft grain with its c-axis normal to the loading direction. The pile-up dislocations were of (a/3) [11 $\overline{2} 0]$ type, gliding on (1lloo). It could be seen that the $\alpha_{\mathrm{s}}+\beta$ two phase region acted as a barrier to slip transmission. 


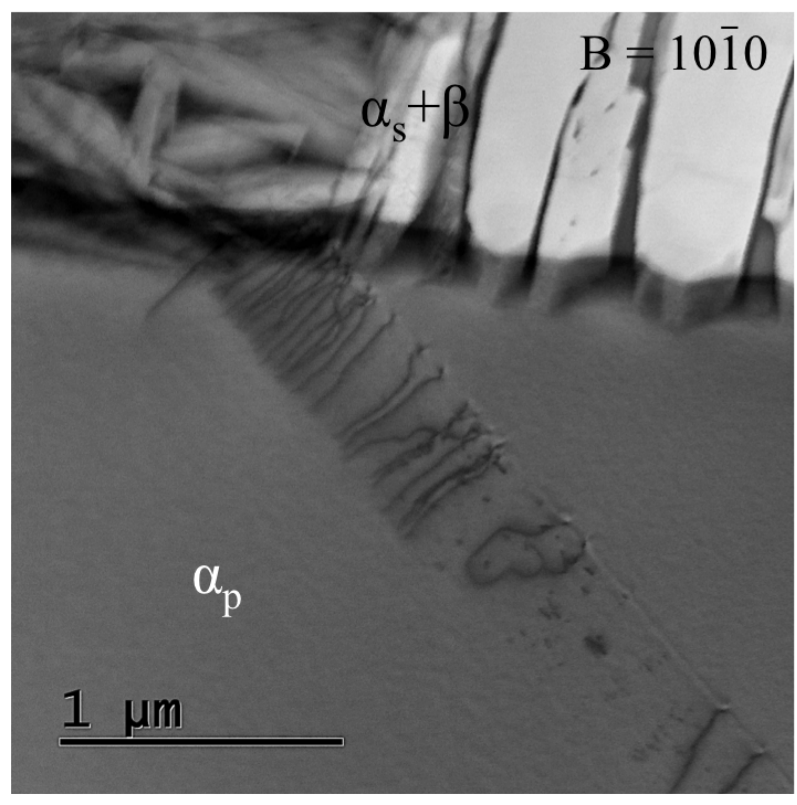

Fig. 2 Planar slip in an $\alpha_{\mathrm{p}}$ grain and the two-phase region acting as a barrier to slip transmission

\subsubsection{Slip/strain transfer across grain pairs:}

Dislocation interactions between grain pairs with different crystallographic orientations were studied, Fig. 3. The grains labelled 1 and 2 have similar orientations with their [01llo] direction oriented along the loading direction, whereas grain 3 has its [01ا1] direction along the loading direction. The composite STEM micrograph in Fig. 3 shows that different slip systems were activated in these grains. The diffraction conditions were selected separately in each grain to show the dislocation structure in each grain. The slip systems, which are interacting across the boundaries, will now be discussed, with the inferred direction of dislocation movement shown by the arrows. Direct slip transmission was observed between grains 1 and 2 where the slip system $\mathrm{A}$ in grain 1 transfers across the boundary into grain 2 as slip system $\mathrm{B}$. High strain contrast was observed near the boundary between grains 2/3 due to the strain associated with the blocked slip band, a result of the misorientation between the grains. The bright field STEM image obtained when grain 2 is tilted to beam direction [01lo] shows clearly the strain contrast 
near the boundary, Fig. 3(b). This is due to the pile-up stress since grain 3 is unfavorably oriented for slip transfer with grain 2. This pile-up stress results in slip C in neighboring grain 3. g.b analysis shows that the dislocations in slip bands A and B are of (a/3) [12 10 ] type gliding on prism plane (10l0), and that the dislocations in slip band $\mathrm{C}$ are of (a/3) [11 $\overline{2} 0]$ type, gliding on the basal plane. Direct slip transfer occurred across the boundary between grains $1 / 2$, where 2> prism slip in grain 1 activated the same type of slip in grain 2. In contrast, strain transfer occurred across the boundary between grains $2 / 3$, where one type of slip in grain 2 activated another type of slip in the neighboring grain 3.

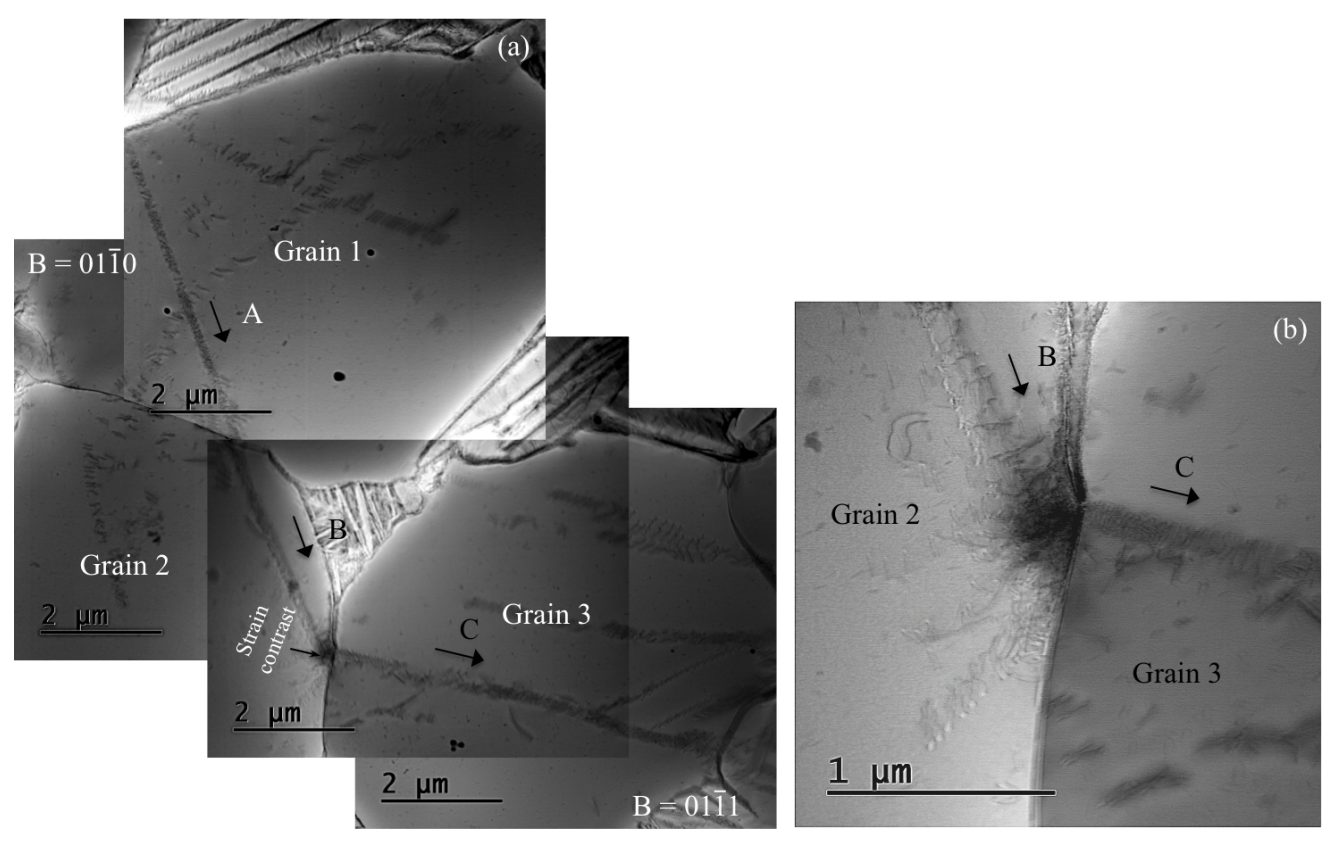

Fig. 3. BF-STEM image showing (a) slip/strain transfer across $\alpha_{\mathrm{p}}$ grains and (b) strain contrast near the boundary between the misoriented grains

\subsubsection{Slip transfer across a misoriented grain pair:}

A grain pair with a misorientation of $30^{\circ}$ was investigated to understand the dislocation interactions near the boundary. The grain pair presented here was composed of a so-called soft 
grain, having its c-axis oriented $\approx 55^{\circ}$ to the loading axis, and a hard grain with its c-axis oriented $\approx 15^{\circ}$ from the loading axis, Fig. 4 (a). The crystallographic orientation of the grain combination was obtained using Transmission Kikuchi Diffraction (TKD) of the TEM foil. The grain boundary is indicated. The orientation relationship of the pair was identified from selected area diffraction (SAD) patterns from these grains when one of the grains was tilted to a zone axis. The SAD patterns of the soft and hard grains are shown in Fig. 5 where $[21 \boldsymbol{l l}]_{\text {soft }} / /[1213]_{\text {hard }}$ and $(10 \mathbb{1} \overline{3}$ )$_{\text {soft }} / /(10 \mathbb{l} 0)_{\text {hard }}$.
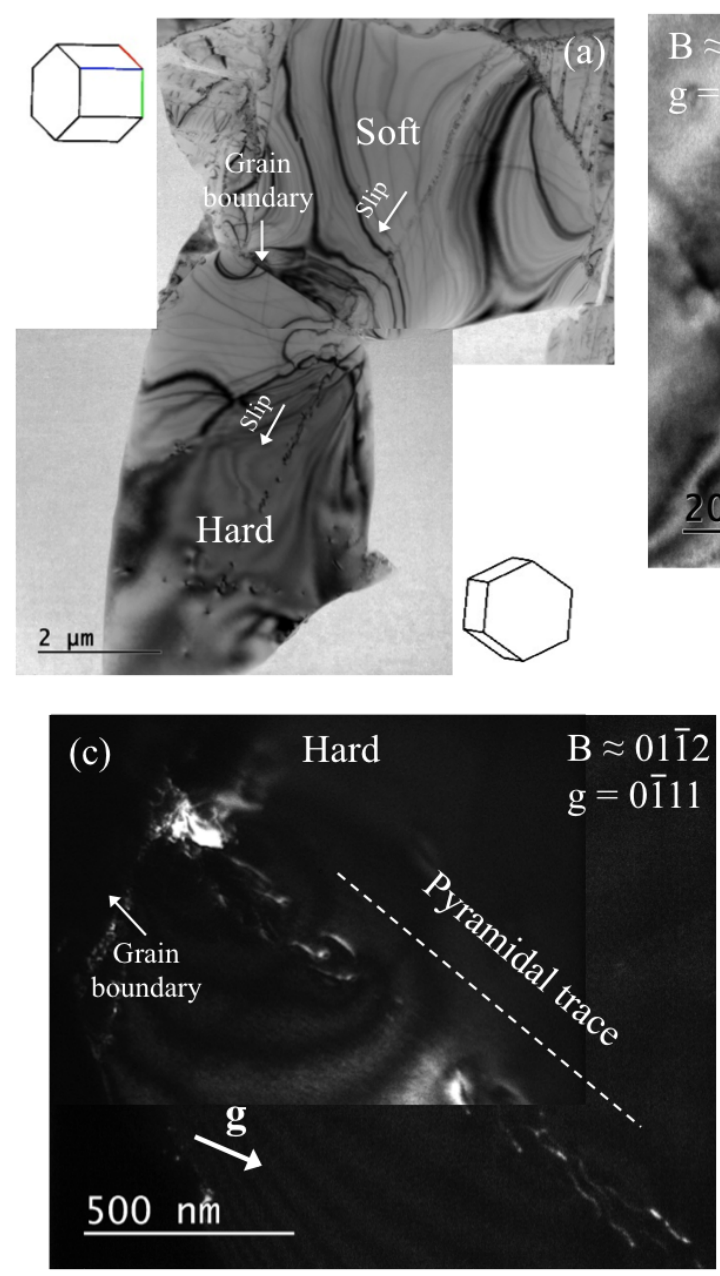
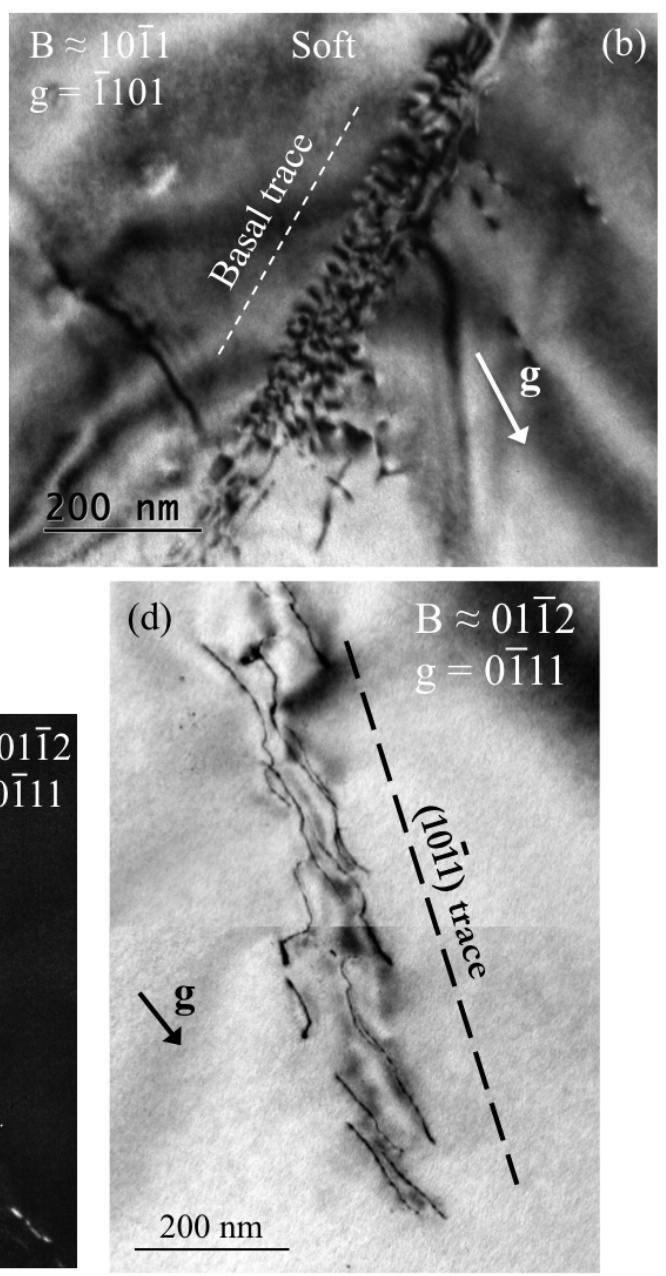
Fig. 4. (a) BF-TEM image showing dislocation interactions between a soft and hard grain. (b) Intense dislocation pile-up in the soft grain. (c) Nucleation of dislocations in the hard grain from the boundary, and (d) cross-slip of dislocations in the hard grain under the two-beam condition.
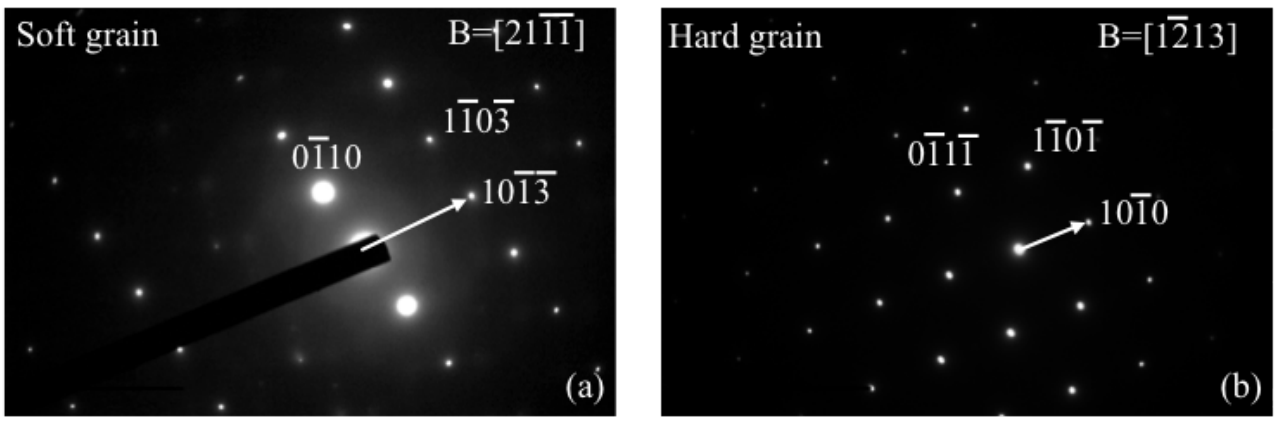

Fig. 5 SAD patterns from (a) soft and (b) hard grain when the hard grain was tilted to the [1 $\overline{2} 13]$ zone

The slip transfer across the soft/hard grain boundary can be seen in Fig. 4(a). Dislocations in the soft grain is piled-up against the grain boundary, Fig. 4(b). These are type dislocations with

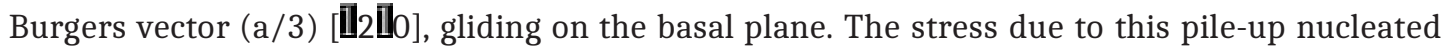
dislocations in the hard grain. These dislocations are of (a/3) [2 $\overline{2} 113$ ] type, gliding on the (10 إl 1 ) pyramidal plane. Hence, the stress concentration due to the pile-up of dislocations in the soft grain activates dislocation sources in the hard grain rather than easing the passage of dislocations through the boundary. So, -type pyramidal dislocations nucleated in the hard grain due to the pile up of $2>$ basal dislocations in the soft grain. The compatibility between active slip systems in adjacent grains was then checked using the Luster and Morris geometric compatibility parameter for slip transfer, m':

$$
\mathrm{m}^{\prime}=\cos \phi \cdot \cos \kappa
$$

where $\phi$ is the angle between the normal to the slip planes and $\kappa$ is the angle between the slip directions in the two grains. This m' value was calculated using Matlab toolbox STABiX [29], Table 1 . The m' values for the observed slip transfer are highlighted by a square and it was found 
to be high for the observed slip systems. Once nucleated, dislocations in the hard grain multiply by cross slip, Fig 3(d). This cross slip was observed between first and second order pyramidal planes. It is believed that cross slip is responsible for dislocation multiplication and patterning in fatigue [30]. Further, the mobility of dislocations on the cross slip planes is lower than on the primary planes [31].

Table 1: Slip transfer parameter (m') value for the grain pair in Fig. 4

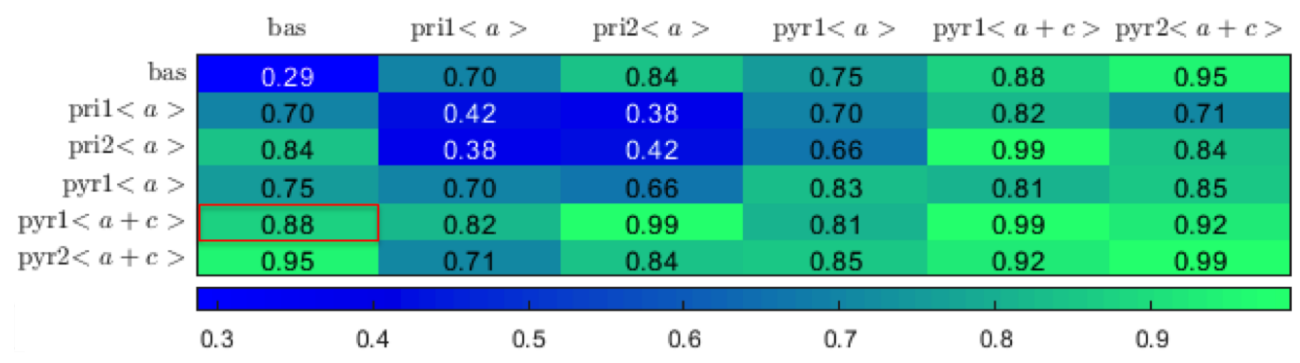

\subsection{Dislocation interactions on the fracture surface:}

We now turn to the dislocation interactions in the foil lifted-out near the crack initiation site. The foil contained an $\alpha_{\mathrm{p}}$ grain bounded by two-phase regions on either. Intense planar pile-ups (Fig. 6a) and dislocation loops (Fig. 6b) were observed in this grain. The dislocation pile-ups were of type with $\mathrm{b}=(\mathrm{a} / 3)[1 \overline{2} 13]$, having mixed character and gliding on the first order pyramidal plane (101), Fig. 6a. The slip bands were 350 - 450 nm in thickness, very much higher than classical pile-ups. The dislocations in this array were also dense and tightly packed. Further, each slip band was not a single pile-up but instead was double ended, Fig. 6a. It was also found that the dislocations on neighboring slip planes in the double ended pile-ups were of opposite sign. The dislocation loops in Fig. $6 \mathrm{~b}$ are found to be of type with Burgers vector $b=(a / 3)[\overline{2} 110]$, gliding on the basal plane. 


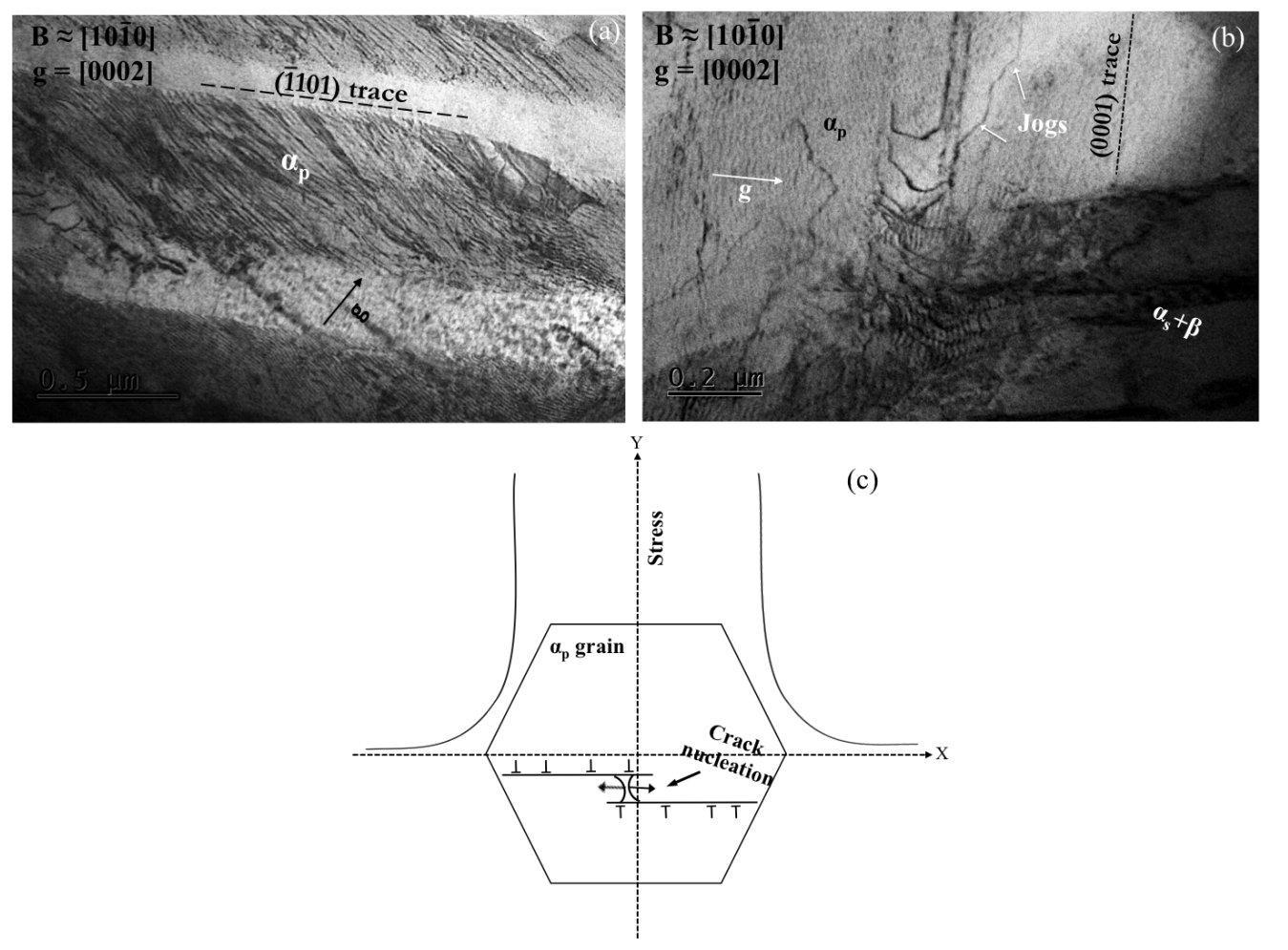

Fig. 6 Bright field TEM micrograph showing (a) double ended pile up in the crack initiated $\alpha_{p}$ grain (b) pile-up of basal dislocations near the boundary between $\alpha_{p}$ and two-phase region and (c) schematic showing the stress field around the grain possessing a double ended pile up

The interactions between the edge component of this dislocation loop and the other dislocations resulted in the formation of superjogs, indicated by arrows in Fig. $6 \mathrm{~b}$. It can be noted that the mixed component of the loops are found to pile-up in the boundary between $\alpha_{s}+\beta$ and $\alpha_{p}$, Fig. $6 \mathrm{~b}$. It was also observed that the slip bands in this grain did not transfer across the boundary between the $\alpha_{\mathrm{p}}$ grain and the two phase region, even though they are intense and large.

Based on these observations the following crack nucleation mechanism is proposed in this case. Near the crack initiation, double ended pile-up was observed in $\alpha_{\mathrm{p}}$ grain. This suggests that during the first half of the loading cycle, pile-up of dislocations with a positive sign occurs on the 
first slip plane. Then, reverse plasticity in the second half cycle causes pile-up of dislocations of negative sign on successive planes, close to the first slip plane. It is also possible for the dislocations in the first plane to reverse completely during the second half of the cycle. If such complete reversal of piled-up dislocations in the first plane occurs, then there is no accumulation of dislocations as a double ended pile-up [32]. Incomplete reversibility of dislocation motion could be realized if the lattice friction stress against dislocation motion is higher in the reverse direction than in the forward direction [32]. This could be rationalised as follows.

The back stress developed by these dislocations is negative in the vicinity of pileup in the first plane, which would cause plastic flow in the reverse direction in the neighboring plane during subsequent reverse loading [32]. The pile-up of negative dislocations on the second plane then causes a positive back stress on the first plane. This back stress enhances the pile-up of positive dislocations during the next stage of forward loading. As the number of cycles increases the number of dislocations in each slip plane as well as the number of piled-up planes increases, hence resulting in the formation of a double ended pile-up, similar to the dislocation distribution near a crack subjected to a shear stress [32-34]. This kind of pile-up is possible only when the dislocation sources are located very close to each other, because for an isolated dislocation source, dislocation motion on a plane becomes reversible as no back stress is produced by the dislocations on a neighbouring plane. Therefore, the reversibility or otherwise of dislocation motion will depend on the statistical distribution of dislocation sources.

Then the embryonic crack might have nucleated from this double ended pile-up as follows. The stress field in this case would be the sum of applied stress and the internal stresses due to the dislocation pile-ups on successive slip planes. In addition, the mixed components of the basal dislocation loops were also found to pile up near the boundary, causing further stress intensification.

The stress distribution due to this double ended pile-up together with the observed dislocation structures in the $\alpha_{p}$ grain is shown schematically in Fig. 6c. Stress intensification takes place near the pile-up tips. A large tensile stress builds up between the two planes of opposite sign 
dislocations in the pile-up, nucleating the facet. The tensile stress at half the distance between the two slip planes is [32]:

$$
\sigma_{\mathrm{xx}}=3 \mathrm{a} \mathrm{n}(\Delta \tau-2 \kappa) / 2 \mathrm{~h}
$$

where $2 \mathrm{a}$ is the grain size, $\mathrm{n}$ is the number of stress cycles, $\Delta \tau$ is the cyclic shear stress applied to the grain, $\kappa$ is the lattice friction stress and $h$ is the slip plane interplanar spacing.

The tensile stress would split the atomic planes along the dislocation lines [35], inset of Fig. 6c. Therefore the large tensile stress resulting from the double ended pile-up appears to be the mechanism responsible for crack nucleation in the $\alpha_{p}$ grain. From the TEM foil, it was observed that the fracture plane is found to be oriented $5-8^{\circ}$ from the basal plane. This near-basal plane cracking rather than true basal plane cracking might be a consequence of the observed jogging of the basal dislocations.

\section{Conclusions}

The dislocation interactions of near alpha titanium alloy Ti6242Si were studied after low cycle fatigue. The investigations were carried out on both gauge section and the crack initiation site of the sample and the following conclusions were made.

- The alloy mainly deforms by planar slip in $\alpha_{\mathrm{p}}$ grains and the two phase region $\alpha_{\mathrm{s}}+\beta$ acting as a barrier for slip transmission.

- Direct slip transfer was observed between similarly oriented grains and slip transfer resulted in nucleation of different kind of dislocations when there is misorientation between grains.

- Strain transfer occurred across the boundary between grains when the misorientation is high, where one type of slip in grain activated another type of slip in the neighboring grain. 
- Double ended pile-up in an $\alpha_{p}$ grain is responsible for crack nucleation in this alloy. Such structures can result from the incomplete reversibility of dislocation motion due to a slightly higher friction stress in the reverse direction than in the forward direction.

- This kind of double ended pile-up results in a large tensile stress, providing a mechanism of crack initiation by plane splitting along the dislocation line. The observation of superjogs on the basal dislocations provides a rationale for why such cracks nucleate near rather than on the basal plane.

\section{Acknowledgements}

The authors wish to acknowledge the contributions of, and useful discussions with Prof D Rugg at Rolls-Royce plc, Prof FPE Dunne and Dr TB Britton at Imperial, and Prof AJ Wilkinson in Oxford, with whom we are funded under the Hexmat EPSRC programme grant EP/K034332/1.

\section{References}

[1] G. S. Hall, S. R. Seagle, H. R. Bomberger In: Titanium Science and Technology, vol. 4. New York: Plenum Press, 1973 p. 2141.

[2] J. K. Tien, J. C. Chesnutt, D.H. Boone, G. W. Goward In: Titanium Science and Technology. New York: Plenum Press, 1973, p. 2517.

[3] G. T. Terlinde, T. W. Duerig, J. C. Williams, Metall. Trans. A 14 (1983) 2101-2115.

[4] Y. Honnorat, Mater. Sci. Eng. A 213 (1996) 115-123.

[5] F. McBagonluri, E. Akpan, C. Mercer, W. Shen, W. O. Soboyejo, Mater. Sci. Eng. A 405 (2005) 111-134. 
[6] J. Qiu, Y. Ma, J. Lei, Y. Liu, A. Huang, D. Rugg, R. Yang, Metall. Mater. Trans. A 45 (2014) 6075-6087.

[7] W. Shen, W. O. Soboyejo, A. B. O. Soboyejo, Metall. Mater. Trans. A 35 (2004) 163-187.

[8] D. Eylon, J. A. Hall, Metall. Trans. A 8 (1977) 981-990.

[9] M. E. Kassner, Y. Kosaka, J. S. Hall, Metall. Mater. Trans. A 30 (1999) 2383-2389.

[10] W. J. Evans, Scr. Metall. 21 (1987) 469-474.

[11] V. Sinha, J. E. Spowart, M. J. Mills, J. C. Williams, Metall. Mater. Trans. A 37 (2006) 15071518.

[12] F. P. E. Dunne, A. Walker, D. Rugg, Proc. R. Soc. A 463 (2007) 1467-1489.

[13] F. P. E. Dunne, D. Rugg, Fatigue Fract. Eng. Mater. Struct. 31 (2008) 949-958.

[14] W. J. Evans, M. R. Bache, Int. J. Fatigue 16 (1994) 443-452.

[15] M. R. Bache, M. Cope, H. M. Davies, W. J. Evans, G. Harrison, Int. J. Fatigue 19 (2002) 83-88.

[16] M. R. Bache, W. J. Evans, J. Eng. Gas Turbines Power 125 (2003) 241-245.

[17] F. P. E. Dunne, D. Rugg, A. Walker, Int. J. Plast. 23 (2007) 1061-1083.

[18] A. L. Pilchak, Scr. Mater. 74 (2014) 68-71.

[19] I. Bantounas, D. Dye, T. C. Lindley, Acta Mater. 57 (2009) 3584-3595.

[20] M. R. Bache, W. J. Evans, H. M. Davies, J. Mater. Sci. 32 (1997) 3435-3442.

[21] K. Kirane, S. Ghosh, Int. J. Fatigue 30 (2008) 2127-2139.

[22] Z. Zheng, D. S. Balint, F. P. E. Dunne, J. Mech. Phys. Solids 96 (2016) 411-427. 
[23] Z. Zheng, D. S. Balint, F. P. E. Dunne, Int. J. Plast. 87 (2016) 15-31.

[24] S. Joseph, I. Bantounas, T. C. Lindley, D. Dye, Int. J. Plast. 100 (2018) 90-103.

[25] L. Wagner, G. Lutjering, Z. Metallkd. 78 (1987) 369-375,.

[26] R. R. Boyer, J. Hall, "Microstructure-property relationships in titanium alloys-critical review.," in Titanium'92: Sci. Technol., 1993, p. 77-88.

[27] S. Joseph, T. C. Lindley, D. Dye, Int. J. Plast.110 (2018) 38-56.

[28] C. Tan, X. Li, Q. Sun, L. Xiao, Y. Zhao, J. Sun, Int. J. Fatigue 75 (2015) 1-9.

[29] D. Mercier, C. Zambaldi, T. R. Bieler, "A Matlab toolbox to analyze slip transfer through grain boundaries," in IOP Conference Series: Materials Science and Engineering, 82, 2015.

[30] S. Suresh, Fatigue of Materials, 2nd edition. Cambridge University Press, 2004.

[31] U. Messerschmidt, M. Bartsch, Mat. Chem. Phy. 81 (2003) 518-523.

[32] K. Tanaka, T. Mura, J. Appl. Mech. 48 (1981) 97-103.

[33] B. A. Bilby, J. D. Eshelby, Dislocations and the theory of fracture. In: In: Liebowitz, H. (Ed.), Fracture-An Advanced Treatise, vol. 1. New York: Academic Press, 1968, p.99.

[34] J. P. Hirth, J. Lothe, Theory of dislocations. New York: Wiley, 1982, p.270.

[35] F. E. Fujita, Acta Metall. 6 (1958) 543-551. 